\title{
Migración y derechos humanos
}

René Vargas

Investigador Utec

\section{Resumen}

Los histórico acuerdos de paz firmados en México al inicio de 1992, abrió un nuevo capítulo de nuestra historia e hizo renacer la esperanza del inicio de una nueva etapa para enrumbarnos hacia la reformulación del Estado en aras de rehacer el tan dañado tejido social; sin embargo, al cumplirse 19 años de ese inédito acontecimiento, el predominio de lo político como factor dominante y su relación dialéctica con lo económico como determinante, propició avances en el primero, pero un enorme déficit en el segundo, con la resultante de una intermitente conflictividad social ante el desmejoramiento de la calidad de vida de la mayoría de la población.

Sobre esta base se sostiene la tesis de que en 1992 concluyó la guerra, pero pasamos a un estado de no paz; ante la inseguridad, el desempleo, el incremento en el costo de la vida y el continuar con una democracia excluyente la población ha vivido una situación de zozobra que ha intentado resolver emigrando y luchando internamente por subsistir, al incumplir el Estado su obligación de garantizarle los derecho civiles, políticos, sociales, económicos y culturales, tal como lo manda la Constitución. Ese es el escenario general heredado por el primer gobierno de izquierda en El Salvador, y, a 18 meses de su mandato, todavía estamos expectantes para ver cumplidos nuestros anhelos de paz, concediéndole al nuevo gobierno el beneficio de la duda, con el deseo de que en el 2011 la economía y su enfoque social pase a ser el factor dominante.

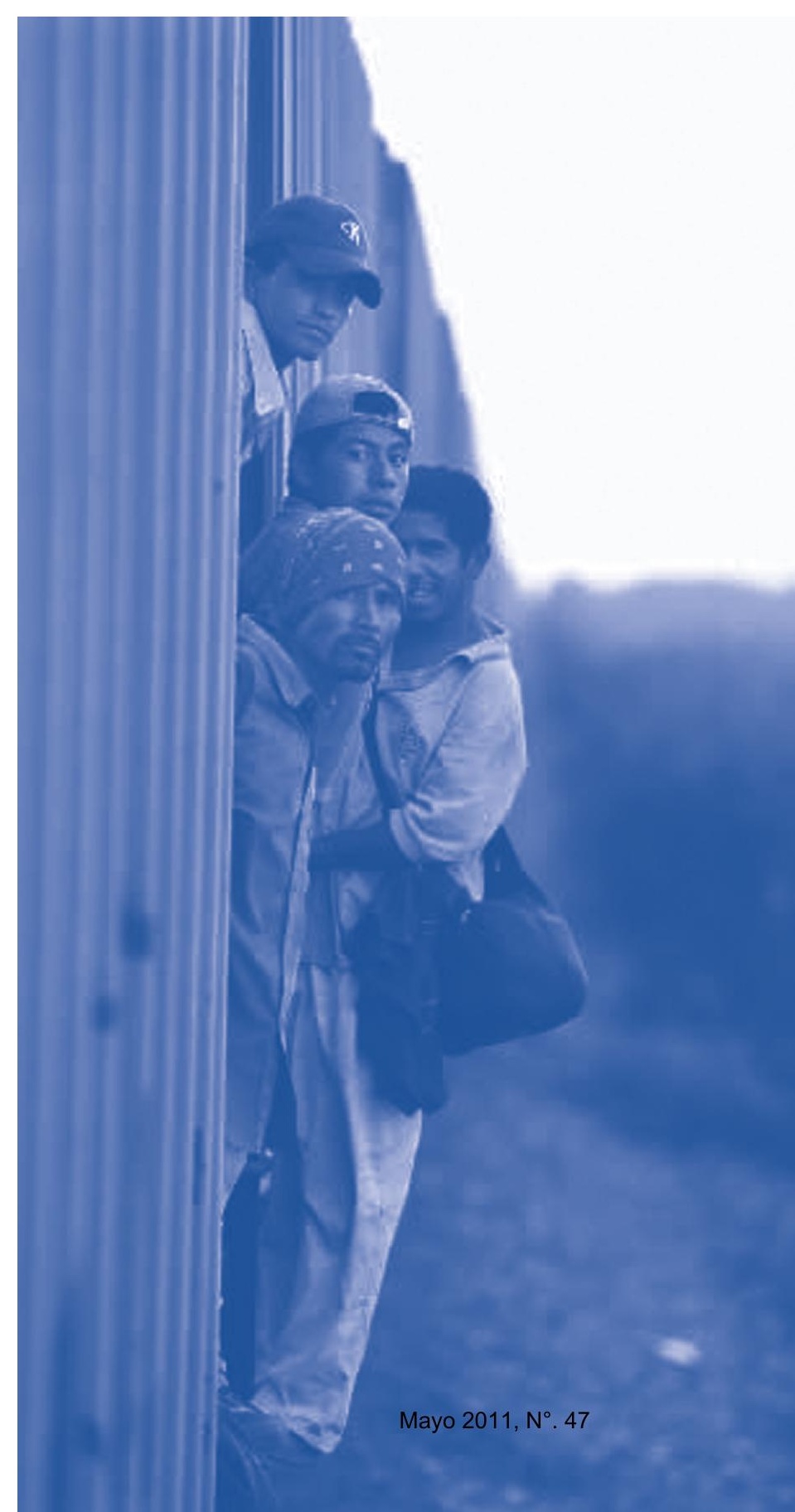




\section{MIGRACIÓN Y DERECHOS HUMANOS "Unir, crecer, incluir"}

\section{Caracterización general de las migraciones}

$\mathbf{L}^{\text {a }}$

a migración es el movimiento que realizan las personas para trasladarse de su lugar de origen hacia otro, ya sea dentro del mismo territorio o extra-fronteras; ya sea de manera temporal o permanente. En el primero de los casos se trata de desplazamientos; lo segundo provoca inmigraciones o emigraciones, dependiendo del enfoque. Ambos fenómenos son de larga data en la historia de la humanidad, que en sus inicios -cuando las fronteras eran inexistentes- fueron realizados por grupos nómadas que vivían de la caza y de la pesca para convertirse luego en sedentarios cultivando la tierra.

En lo que a nuestra América se refiere, una de las teorías acerca de los orígenes de la población en el nuevo mundo parte del relato sobre la inmigración de hordas mongólicas nómadas a través del estrecho de Bering, quienes -en el transcurso de miles de años- avanzaron por las costas del Pacífico hacia el sur hasta poblar totalmente nuestras tres Américas: Norte, Centro, Sur y el Caribe; pero es a partir de la invasión española y el consiguiente proceso de conquista que se había de producir un constante flujo de pobladores de ultramar, unos escapando de las guerras entre católicos y protestantes, otros motivados por la buena nueva de las riquezas encontradas en nuestro continente.

Con el correr de los años la dinámica de esa traslación fue cambiando, y en el presente somos los latinoamericanos y caribeños quienes buscamos nuevos horizontes, generalmente en situación de ilegalidad; de acuerdo con estudios sobre la actual tendencia, se estima una cifra un poco superior a los 30 millones que han emigrado desde nuestra región, lo que constituye cerca del 15\% del movimiento total a escala mundial, siendo Estados Unidos el destino preferente, país que calcula en más o menos 18 millones la cantidad recibida desde México, el Caribe, Centro y Sur América. Pero, ¿cuál es la causa que motiva a tanto latinoamericano y caribeño a emigrar de sus países de origen? ¿Qué consecuencias sociales ha tenido ese flujo migratorio? La búsqueda de respuestas a tan complejo problema ha motivado un prolífico trabajo de investigación, intentando explicaciones políticas, económicas, sociales, demográficas, culturales y, últimamente, desde la apertura generada por la nueva fase del capitalismo: la globalización de la economía mundial.

\section{Migraciones en El Salvador}

En lo que a El Salvador respecta, los movimientos migratorios deben ser abordados dentro de ese contexto histórico, partiendo de los estudios acerca de la inmigración de los primeros pobladores que ingresaron a nuestro territorio en la época precolombina, proceso del que existen más hipótesis y estimaciones que fundamentos reales, por lo que se requiere continuar con la profundización de la investigación sobre el tema; igual esfuerzo debemos realizar en lo referido a las causas y efectos de las emigraciones, así como al problema de los desplazamientos internos, específicamente los provocados por el modelo agroexportador basado en la producción extensiva del café, con la perniciosa expulsión de los campesinos de las tierras comunales y ejidales hacia zonas cada vez más marginales ante la ampliación de la frontera agrícola con los cultivos de caña de azúcar y algodón. En la medida que el proceso avanzó, los desplazamientos fueron obligando a la búsqueda de tierras fuera de nuestras fronteras- de hecho, cada vez más escazas dada la dimensión del territorio-inicialmente emigrando hacia el vecino país de Honduras, en donde a finales de los años 60 se habían asentado cerca de 100 mil salvadoreños. 
Una segunda etapa del referido proceso se generó a partir de los años 50 por la atracción que los principales centros urbanos ejercieron sobre la población rural a partir del impulso del modelo de crecimiento hacia adentro o sustitución de importaciones. El buscar oportunidades de trabajo como asalariados en la actividad industrial y comercial, especialmente en el campo de la construcción, atrajo un flujo de mano de obra no calificada que comenzó a habitar en lugares no aptos para la vivienda, dando paso a los denominados cordones de miseria, con el consecuente riesgo de sus vidas ante el efecto de la alta vulnerabilidad del país ante el impacto de los fenómenos naturales. Pero, además, la falta de oportunidades y la imposibilidad de movilidad en un contexto económico, social y político excluyente, acrecentaron el denominado sector informal de la economía y dio paso además al mito del "sueño americano".

Un tercer momento lo constituyó el acrecentamiento de la conflictividad política a partir de la década de los 70, la cual desembocó en una confrontación armada con su escenario general en la zona rural, especialmente en toda la parte norte, paracentral y oriental del país. Si las otras veces fue la preeminencia de la necesidad económica el factor potenciador del movimiento poblacional, esta vez lo causó la situación político-militar, provocando que grandes cantidades de familias se fueran desplazando hacia lugares menos riesgosos o emigrando para escapar de la violencia indiscriminada, ampliándose la estratificación social de ambas dinámicas a los sectores de clase media, en su mayoría profesionales, quienes -a diferencia de los sectores pobres urbanos y rurales- se han visto expatriados en su mayoría cumpliendo las exigencias legales de los países receptores o han tenido la posibilidad de trasladarse a ciertos municipios en viviendas propias o alquiladas.

Como puede verse, los desplazamientos y emigraciones de los salvadoreños tienen un origen multicausal e incluso han venido evolucionando de acuerdo con las distintas dinámicas históricas, que en cada coyuntura han actuado como catalizadores de dichos procesos, afectando a diversos sectores de la población; el factor demográfico, los desastres provocados por los fenómenos naturales, la pérdida de fuentes de empleo, el abandono de la agricultura, el deterioro de la calidad de vida, la violencia social, la democracia excluyente, las políticas de Estado, los modelos económicos implantados, son todos variables objetivas que han influido en la salida de grupos familiares hacia otros lares o incrementado la concentración demográfica en determinados centros urbanos del país, con familias numerosas viviendo hacinadas en espacios habitacionales que no reúnen las mínimas condiciones para una vida digna de cualquier ser humano.

\section{La responsabilidad del Estado salvadoreño}

Cuando nuestro país surge como Estado-Nación, se rescata el pensamiento filosófico-político elaborado por los pensadores del Renacimiento y la llustración en cuanto a la razón de ser de esa entidad creada jurídicamente. Siendo su finalidad buscar el bien común y su principio axiológico fundamental garantizar la libertad, el Estado se convirtió en un sujeto de deberes, obligado a proteger y reconocer los derechos del demos o soberano. Ese es el sustrato de todo el constitucionalismo salvadoreño desde su primera Constitución en 1824, expresado en la de 1886 en su artículo $8^{\circ}$, reafirmado en las de 1950 en su artículo $2^{\circ}$ y de 1983 en su artículo $1^{\circ}$. El Salvador reconoce a la persona humana como el origen y el fin de la actividad del Estado, que está organizado para la consecución de la justicia, la seguridad jurídica y del bien común. En consecuencia, es obligación del Estado asegurar a Ios habitantes de la República, el goce de la libertad, la salud, la cultura, el bienestar económico y la justicia social".

Este artículo se adhirió a la producción intelectual de los dos trascendentales movimientos histórico-políticos de la huma- 
nidad en lo referido a los derechos fundamentales o humanos. El del Estado burgués de derecho y su amplio desarrollo de las garantías civiles y políticas, instituidos en la Revolución francesa bajo el título de "Derechos del hombre y del ciudadano", y conocidos en la jerga jurídica como derechos de primera generación. El segundo corresponde al Estado social de derecho y la "Declaración universal de Derechos Humanos", aprobada y adoptada por la Asamblea General de las Naciones Unidas en diciembre de 1948, denominados derechos de segunda generación. Ambos contenidos han sido incluidos en cada época histórica por los constituyentes, y actualmente obligan a su cumplimiento por parte del Estado al estar contemplados en la Constitución de 1983 en su Título II, Capítulo I, Artículos del 2 al 28 y en el Capítulo II, artículos del 32 al 70, respectivamente.

\section{La realidad imperante}

Lo primero que se debe establecer, en consonancia con el título de este artículo, es que luego de casi 190 años de vida institucional, el Estado salvadoreño ha reprobado ante el soberano la materia de "Derechos humanos", por cuanto ha incumplido su obligación constitucional de salvaguardar el bienestar de la población, provocando internamente una recurrente conflictividad social estructural hasta desembocar en una confrontación armada que nos ha dejado profundas heridas aún no sanadas y un trasiego de recurso humano interno y externo, que solo en Estados Unidos representa actualmente un aproximado del $25 \%$ de la población del país, la cual ronda los 6 millones de habitantes según el último censo, y una fuerte concentración demográfica en determinados municipios del país.

A 19 años de la firma de los acuerdos de paz, son múltiples las voces que coinciden en señalar la precaria situación de la mayoría de los salvadoreños, lo que políticamente permite afirmar que hemos pasado de una situación de guerra a otra

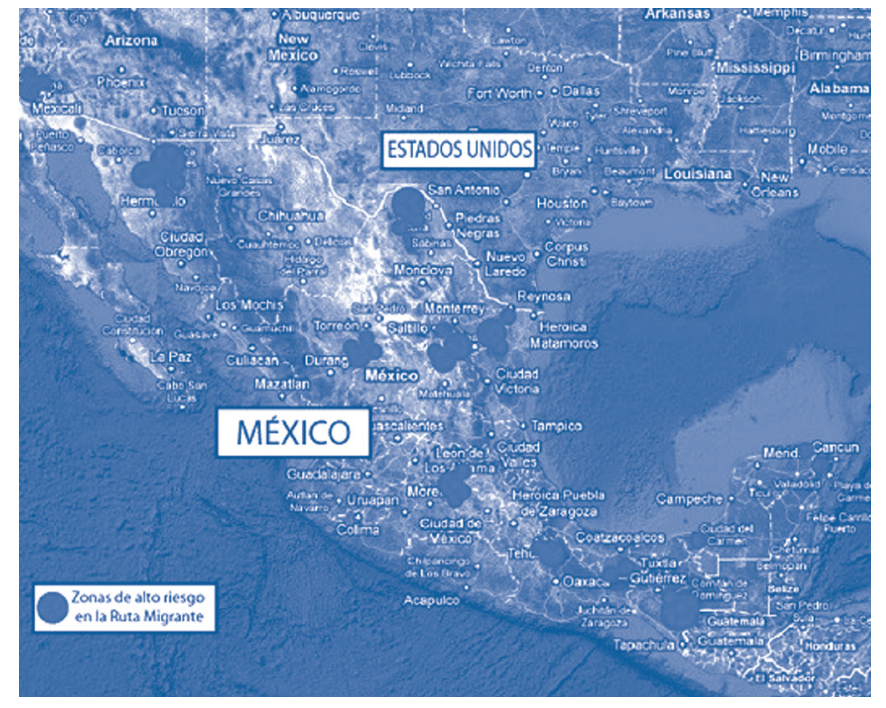

de no paz, es decir, a un ambiente de inseguridad individual y a una frustración colectiva al no superarse las contradicciones sistémicas causantes de la violencia estructural, estado de cosas que, por el contrario, se fue profundizando a partir del nuevo pacto. Para evidenciar la aseveración anterior recurro al informe del "Proyecto de Análisis Político y Análisis Prospectivo para Fortalece la Gobernabilidad Democrática" (Paper), como parte del programa de las Naciones Unidas para el Desarrollo titulado "El Salvador. El camino hacia un nuevo ciclo político: Escenarios de gobernabilidad 20092010". Tomo de aquel algunos datos para perfilar el ambiente en cuanto a los derechos humanos de segunda generación:

- Una inflación acumulada al 2008 del 5\% y su efecto en la canasta básica alimentaria, que a marzo del 2009 era 15,5\% mayor al costo de junio del 2007 en el área rural y $20 \%$ para los habitantes urbanos.

- Un incremento de la pobreza, que entre el 2006 y el 2007 pasó del $30,7 \%$ de hogares al $34,5 \%$, siendo del $29,8 \%$ urbana y $43,8 \%$ rural.

- Las perspectivas del crecimiento del PIB para el 2010 según el FMl es del 0,5\% 
- Una reducción del 7,5\% en el ingreso de divisas durante el 2009 por remesas de compatriotas en el exterior, en comparación con el 2008, el cual es su principal fuente y beneficia a un buen porcentaje de la población, la que las utiliza básicamente para el consumo.

Como se dice en el lenguaje coloquial, "para muestra un botón". Aplicado al tema significa que, habiendo muchos más datos para demostrar la tesis sobre la reprobación del Estado, basten los mencionados como fuente de análisis e interpretación de la realidad imperante al estar por conmemorar 19 años de la firma del nuevo contrato social y de haberse agotado el primer decenio del siglo XXI. ${ }^{1}$ En ambos espacios lo positivo ha sido el lograr al fin una verdadera alternabilidad en el gobierno, un transitar pacífico hacia un presidente del Ejecutivo respaldado por un partido de izquierda y la apertura de un nuevo escenario para cambiar la situación de los derechos económicos, sociales y culturales, así como reducir el ambiente de violencia e inseguridad que vivimos. Sin embargo, las condiciones de vida se han seguido deteriorando para la mayoría de la población, cundiendo otra vez la desesperanza y la frustración, expresados en los constantes reclamos de diversos sectores: tomas de vías, huelgas, paros del transporte y más recientemente la ocupación de Catedral por parte de los lisiados de guerra. El haber concluido el año 2010 con un promedio de 11 asesinatos por día, una tasa de desempleo de casi el $8 \%$ con un subempleo arriba del $40 \%$, y una pérdida del poder adquisitivo de los salarios mínimos nominales (\$97.20 para trabajadores agropecuarios, \$207.68 en los de comercio y servicios, \$203.10 en la industria y $\$ 173.78$ en maquila textil y confección) ante el incremento de la canasta básica alimentaria que, según el Centro para la Defensa del Consumidor, a octubre de 2010 era de $\$ 181.75$, agravada en el área rural por el incremento en el precio del frijol, explica las preocupaciones y los retos que está enfrentando el "gobierno del cambio."

En cuanto a los emigrantes, a pesar de la prórroga del TPS, su situación sigue siendo complicada, y ya en el primer mes del 2011 ha ingresado un primer contingente de deportados. El Estado, que podría beneficiarse de ese flujo de recurso humano exportado, ha sido incapaz de retribuirles a nuestros compatriotas su aporte, incluso negando, a quienes han adquirido la calidad jurídico-política de "ciudadanos", el elemental derecho del sufragio al forzarlos a cumplir esa obligación en el país, sin considerar su situación migratoria. La falta de oportunidades sigue fomentando la necesidad de emigrar, a pesar de los cada vez mayores controles para evitar la llegada de compatriotas a su destino final, a lo que debe agregarse los enormes riesgos que se corren en el trayecto al exponerse al secuestro, el chantaje y hasta la pérdida de la vida, como ha sucedido recientemente con los casos de Tamaulipas y Oaxaca.

\section{Escenarios futuros}

Al iniciar un nuevo decenio en el 2011, el presente todavía se encuentra atrapado por el pasado y eso ha creado un futuro incierto para nuestra nación; el problema de la inseguridad producto del accionar de redes delincuenciales creadas para lavar dinero así como traficar con drogas, armas y personas, la poca credibilidad en las instituciones del Estado, las secuelas de la corrupción, la polarización política, la extrema vulnerabilidad evidenciada con los estragos provocados por los fenómenos naturales, la degradación ambiental, son escollos importantes que salvar si se quiere ir construyendo un El Salvador diferente, con la capacidad de enfrentar las significativas deficiencias en las coberturas de salud, educación, nutrición, empleo, tal como lo manda la Constitución.

\footnotetext{
1 Para tener una visión más amplia sobre el estado de cosas se sugiere al lector consultar el "Informe sobre Desarrollo Humano El Salvador 2010, de la pobreza y el consumismo al bienestar de la gente", así como el segundo informe de coyuntura legal e institucional de Fusades, ambos presentados recientemente.
} 


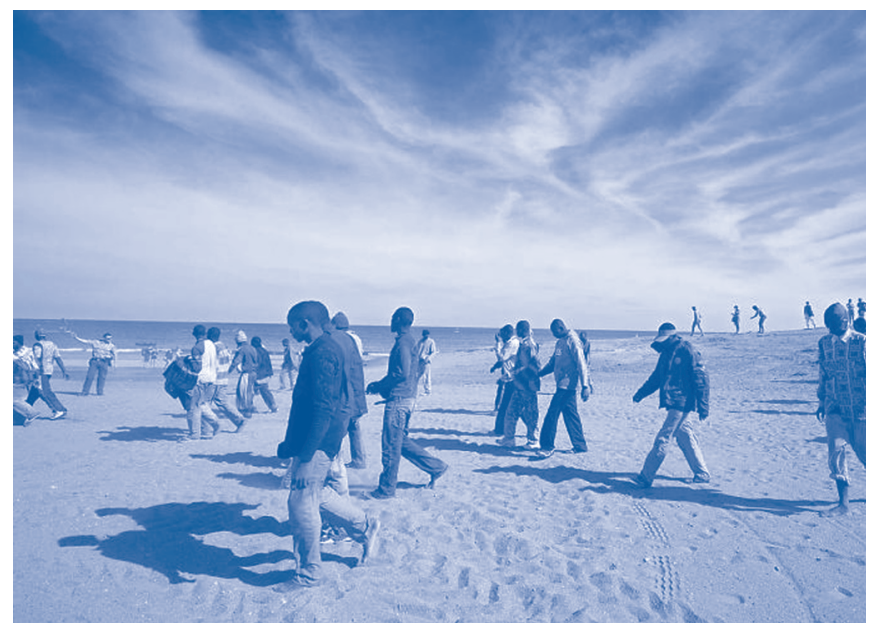

El reciente capítulo de nuestra historia, iniciado con el inédito acontecimiento del triunfo electoral de un partido de izquierda, va camino a cumplir su segundo año de gobierno, y todavía resuenan en el ambiente las palabras del nuevo presidente "No tenemos derecho a cometer errores" y "haremos un gobierno de unidad nacional que gobernará para todos". En todo este tiempo, aparte del esfuerzo político por despolarizar al país, el Ejecutivo a tratado de palear la situación económica de la colectividad con medidas de emergencia, especialmente en el ramo de educación en donde se suministró zapatos, uniformes, útiles escolares y comida a estudiantes de escuelas estatales, pero sin lograr reactivar Ios motores de la economía. El haberse ganado la confianza de las instituciones financieras internacionales hace prever un escenario general, además impostergable para el 2011, en donde la inversión pública pueda permitir el despegue, poniendo el énfasis en políticas de Estado con enfoque social.

En lo que respecta a los derechos civiles y políticos, al celebrarse el décimoctavo aniversario de la firma de los Acuerdos de Paz, el presidente pidió perdón a nombre del Estado a los familiares de las víctimas de crímenes cometidos por el Ejército, los cuerpos de seguridad y las organizaciones paramilitares, e hizo lo mismo al conmemorarse treinta años del asesinato de monseñor Romero, como también honró la memoria de los padres jesuitas, otorgándoles la más alta distinción del país. Todos estos hechos han constituido acontecimientos históricos sin precedentes en el ámbito gubernamental, generándose la expectativa de que al fin se diría la realidad al pueblo sobre los hechos acaecidos en los años de la guerra, como parte de la trilogía verdad-justicia-perdón para sanar las heridas provocadas por la lucha armada. Sin embargo, la desaparición del activista comunitario Marcelo Rivera, quien lideraba un movimiento en contra de la explotación de minas en el departamento de Cabañas, puso a prueba el compromiso del gobierno y del sistema de justicia por eliminar la impunidad del pasado, hecho que hasta el momento sigue sin ser resuelto, generando razonables dudas en la sociedad, sobre todo porque han sucedido otros casos en ese sector que están en las mismas condiciones, así como por el clamor de los familiares de las víctimas de la guerra y de organizaciones nacionales e instituciones internacionales para que el gobierno derogue la ley de amnistía.

Si está situación devela un futuro incierto en cuanto al respeto a los derechos humanos de primera generación, mayores son los nubarrones que se ciernen sobre los de segunda generación. El constante incremento en el combustible produce un efecto multiplicador en el resto de la economía, con un espiral creciente en el sistema general de precios, impactando negativamente las ya deterioradas finanzas familiares, ampliando la brecha de la crónica desigualdad social, histórico obstáculo al avance del desarrollo humano en Latinoamérica y el Caribe. Los esfuerzos por enfrentar la pobreza con medidas, como la aplicación racional del subsidio al gas, para que realmente ayude a la economía de quienes lo necesitan, se ven contrarrestados con incrementos en el costo del alumbrado y otros bienes de consumo básico para la población, escenario complicado si se toma en cuenta el estado de las finanzas públicas para impulsar las urgentes políticas sociales, así como el comportamiento de variables exógenas y, por tanto, imposibles de controlar por el actual gobierno. 


\section{Epílogo}

El 2011 es un año decisivo para accionar las políticas públicas que permitan cumplir con los compromisos asumidos por el presidente del ejecutivo en su discurso inicial, comenzando por demostrar transparencia y efectividad en la administración de los recursos recibidos del sistema financiero internacional y su aplicación en la generación de empleos. Si en su primer año el esfuerzo se orientó hacia lograr cierta estabilidad política mediante la reconstrucción del tejido social a través del diálogo para validar su promesa de luchar por la unidad nacional como paso previo para la gobernabilidad democrática, el nuevo escenario le plantea la exigencia de convertir en factor dominante lo económico, por cuanto pronto estaremos inmersos de nuevo en una lucha por el poder, pues se avecinan dos procesos electorales dentro de su período y sabido es que son momentos en donde lo político desplaza a otros aspectos de la dinámica social, por mucho que se tomen medidas para evitar la participación activista de los funcionarios públicos en dichos procesos.

Los desplazamientos y la emigración causados por la falta de oportunidades pueden ser reducidos si se logra generar polos de desarrollo y oportunidades de trabajo que permitan a la población visualizar un futuro mejor para sus familias. Este es el desafío para comenzar a fundar las bases sobre las cuales construir en el largo plazo un mejor El Salvador, un país que realmente logre finalmente vivir en paz, en donde todos seamos sujetos del proceso y razón de ser real del Estado, como lo menciona el reciente "Informe sobre Desarrollo Humano El Salvador 2010". elaborado por el PNUD: "Siendo el empleo y el poder adquisitivo tan cruciales para la vida de las personas, es natural que los diagnósticos sobre su comportamiento, así como la creación de un marco apropiado de políticas públicas que amplíen las oportunidades de la gente en estos ámbitos, estén en el centro del enfoque de desarrollo humano". Desde la academia apoyamos el esfuerzo por hacer realidad la utopía concreta de que un El Salvador mejor es posible, sueño que exige a todos los sectores de la sociedad hace propio el reto de "Unir, crecer, incluir".

\section{Referencias}

- Constitución Política de 1983, PNUD, “Informe sobre DesarroIlo Humano El Salvador 2010, de la pobreza y el consumismo al bienestar de la gente," San Salvador, 2010.

- "El Salvador, el camino hacia un nuevo ciclo político: Escenarios de gobernabilidad 2009-2010," San Salvador, 2009.

- Vargas, R.E., (2010), “Cumplimiento institucional en la defensa de los derechos humanos a partir de los acuerdo de paz," inédito. 